\title{
Wolfgang Drost, L'image immaculée de Baudelaire champion de la modernité
}

\section{Mario Richter}

\section{(2) OpenEdition}

1 Journals

\section{Edizione digitale}

URL: http://journals.openedition.org/studifrancesi/4436

DOI: $10.4000 /$ studifrancesi.4436

ISSN: 2421-5856

\section{Editore}

Rosenberg \& Sellier

\section{Edizione cartacea}

Data di pubblicazione: 1 settembre 2016

Paginazione: 356

ISSN: 0039-2944

\section{Notizia bibliografica digitale}

Mario Richter, «Wolfgang Drost, L'image immaculée de Baudelaire champion de la modernité », Studi

Francesi [Online], 179 (LX | II) | 2016, online dal 01 septembre 2016, consultato il 18 septembre 2020. URL : http://journals.openedition.org/studifrancesi/4436; DOI : https://doi.org/10.4000/studifrancesi. 4436

Questo documento è stato generato automaticamente il 18 settembre 2020.

\section{(c) (1)}

Studi Francesi è distribuita con Licenza Creative Commons Attribuzione - Non commerciale - Non opere derivate 4.0 Internazionale. 


\title{
Wolfgang Drost, L'image immaculée de Baudelaire champion de la modernité
}

\author{
Mario Richter
}

\section{NOTIZIA}

WOLFGANG DROST, L'image immaculée de Baudelaire champion de la modernité, «Romanistische Zeitscheift für Literaturgeschichte / Cahiers d'Histoire des Littératures Romanes» 39, 3/4, 2015, pp. 357-365.

1 Si tratta della replica alle osservazioni e alle critiche dell'intervento con il quale Schellino (se ne veda qui sopra la scheda) ha sostanzialmente inteso illustrare e difendere la "modernità" di Baudelaire di fronte a Manet, "modernità" messa in dubbio da Wolfgang Drost in un suo precedente articolo. Tornando a discutere il rapporto Baudelaire/Manet, Drost non rinuncia alla sua posizione in proposito e anzi corrobora ulteriormente la sua perplessità (come ironicamente appare già dalla formulazione data al titolo del suo articolo) di fronte alla "modernità" di cui l'autore delle Fleurs du Mal sarebbe l'intoccabile paladino. «Accepter l'incompréhension même partielle de Baudelaire face à Manet - si chiede infatti - serait-ce une faille dans notre image du poète, champion de la modernité?». Così l'intero intervento ha il principale scopo di mettere in luce le oggettive e diverse esitazioni manifestate da Baudelaire di fronte a taluni significativi aspetti della "modernità" che nel suo tempo si andava affermando e della quale Manet era un convinto sostenitore all'insegna di un auspicato "realismo". Dopo aver riaffermato una incontestabile "nuance négative" nella frase scritta da Baudelaire a Manet («Vous n'êtes que le premier dans la décrépitude de votre art»), Drost sostiene in primo luogo un principio di metodo, secondo il quale non è buona norma valutare i critici d'arte dei secoli passati alla luce del nostro gusto e delle nostre attuali valutazioni estetiche. Sulla base di fatti e raffronti con i giudizi degli artisti dell'epoca, lo studioso cerca dunque di accertare l'effettiva estetica di Baudelaire arrivando in tal modo ad affermare che il poeta «était tiraillé entre son amitié pour Manet et ses convictions de critique», convinzioni critiche che, col conforto di 
Delacroix di cui approvava e ammirava il «surnaturalisme», gli facevano invocare «une idée mystique de transcendance que la clarté et la monumentalité des œuvres de Manet ne possèdent pas». Drost conclude dunque la sua replica tornando a ribadire che «Baudelaire se rallie moins à la modernité de Manet mais donne plutôt des impulsions au symbolisme en peinture».

2 Se mi è consentito d'intervenire molto brevemente in questa disputa, credo che un testo dal quale è possibile desumere indicazioni decisive in proposito sia presente nelle Fleurs du Mal, ossia nell'opera poetica a cui Baudelaire ha affidato con piena libertà (senza ipocrisia) tutte le sue convinzioni più autentiche e profonde (si ricordi: «Faut-il vous dire à vous qui ne l'avez pas plus deviné que les autres, que dans ce livre atroce, j'ai mis tout mon cœur, toute ma tendresse, toute ma religion (travestie), toute ma haine?»). Intendo riferirmi al "sonetto" L'Idéal, pubblicato per la prima volta nel $1851 \mathrm{e}$ riproposto senza modifiche nelle tre successive edizioni delle Fleurs (1857, 1861, 1868 postuma). In quei versi dedicati all'arte Baudelaire rifiuta senza mezzi termini e soprattutto senza eccezioni l'intero suo secolo, che definisce un "siècle vaurien», apparendogli questo interamente votato a un'arte priva di vigore, esangue, riconducibile nella sua globalità alle "pâles roses» di un Gavarni, l'artista che si può appunto ritenere espressione di una generale «décrépitude». Quanto ai «Phares», che si concludono con Delacroix, ci sono elementi sufficienti - se valutati nella consequenzialità poetico-tematica del libro, s'intenda la "rhétorique profonde" - a renderne plausibile una interpretazione che non escluda il sarcasmo (cfr. la mia Lecture intégrale des Fleurs du Mal, Genève, Slatkine, 2001, t. I, pp. 86 ss). Il cuore del "Poète", dice Baudelaire ne L'Idéal, può trovare soddisfazione soltanto in valori che vanno ben al di là di un riduttivo e inconcludente "réalisme" inteso come comune obiettivo di un'estetica ispirata per un verso al positivismo e per un altro al Parnasse: è un cuore che può trovare adeguato nutrimento soltanto nel "surnaturalisme" di un'«âme puissante au crime» com'è quella shakespeariana di Lady Macbeth, del «Rêve d'Eschile éclos au climat des autans» o della Notte di Michelangelo, i cui «appas» sono stati «façonnés aux bouches des Titans». Sembra dunque che non avesse poi torto Jules Breton (opportunamente citato da Drost fin dall'inizio del suo intervento) ad affermare che «les esprits qui identifiaient l'influence de Baudelaire en littérature à celle de Manet en peinture me semblent se tromper étrangement» arrivando a precisare che «l'un serait plutôt l'antithèse et l'ennemi de l'autre». 